\title{
Article \\ Check-Valve Design in Enhancing Aerodynamic Performance of Flapping Wings
}

\author{
Lung-Jieh Yang ${ }^{1}{ }^{\mathbb{D}}$, Reshmi Waikhom ${ }^{1}{ }^{*} \mathbb{D}$, Wei-Chen Wang ${ }^{1}$, Vivek Jabaraj Joseph ${ }^{1}$, Balasubramanian Esakki ${ }^{2}$, \\ Neethish Kumar Unnam ${ }^{1}$, Xiu-Han $\mathrm{Li}^{3}$ and Chi-Yuan Lee ${ }^{4}$
}

1 Department of Mechanical and Electromechanical Engineering, Tamkang University, Tamsui 251301, Taiwan ljyang@mail.tku.edu.tw (L.-J.Y.); bmw001234567@gmail.com (W.-C.W.); vivekjabarajwork@gmail.com (V.J.J.); vamsi.neethish@gmail.com (N.K.U.)

2 Department of Mechanical Engineering, Vel Tech Rangarajan Dr Sagunthala R\&D Institute of Science and Technology, Chennai 600062, India; esak.bala@gmail.com

3 School of Electronics and Information Engineering, Beijing Jiaotong University, Beijing 100044, China; lixiuhan@bjtu.edu.cn

4 Yuan Ze Fuel Cell Center, Department of Mechanical Engineering, Yuan Ze University, Taoyuan 32003, Taiwan; cylee@saturn.yzu.edu.tw

* Correspondence: reshmiwaikhom@gmail.com

Citation: Yang, L.-J.; Waikhom, R.; Wang, W.-C.; Jabaraj Joseph, V.;

Esakki, B.; Kumar Unnam, N.; Li,

X.-H.; Lee, C.-Y. Check-Valve Design in Enhancing Aerodynamic

Performance of Flapping Wings. Appl.

Sci. 2021, 11, 3416. https://doi.org/

10.3390/app11083416

Academic Editor: Hoon Cheol Park

Received: 8 March 2021

Accepted: 8 April 2021

Published: 10 April 2021

Publisher's Note: MDPI stays neutral with regard to jurisdictional claims in published maps and institutional affiliations.

Copyright: (c) 2021 by the authors. Licensee MDPI, Basel, Switzerland. This article is an open access article distributed under the terms and conditions of the Creative Commons Attribution (CC BY) license (https:// creativecommons.org/licenses/by/ $4.0 /)$.

\begin{abstract}
A flapping wing micro air vehicle (FWMAV) demands high lift and thrust generation for a desired payload. In view of this, the present work focuses on a novel way of enhancing the lift characteristics through integrating check-valves in the flapping wing membrane. Modal analysis and static analysis are performed to determine the natural frequency and deformation of the checkvalve. Based on the inference, the check-valve opens and closes during the upstroke flapping and downstroke flapping, respectively. Wind tunnel experiments were conducted by considering the two cases of wing design, i.e., with and without a check-valve for various driving voltages, wind speeds and different inclined angles. A $20 \mathrm{~cm}$-wingspan polyethylene terephthalate (PET) membrane wing with two check-valves, composed of central disc-cap with radius of $7.43 \mathrm{~mm}$, supported by three S-beams, actuated by Evans mechanism to have $90^{\circ}$ stroke angle, is considered for the $10 \mathrm{gf}$ (gram force) FWMAV study. The aerodynamic performances, such as lift and net thrust for these two cases, are evaluated. The experimental result demonstrates that an average lift of $17 \mathrm{gf}$ is generated for the case where check-valves are attached on the wing membrane to operate at $3.7 \mathrm{~V}$ input voltage, $30^{\circ}$ inclined angle and $1.5 \mathrm{~m} / \mathrm{s}$ wind speed. It is inferred that sufficient aerodynamic benefit with $68 \%$ of higher lift is attained for the wing membrane incorporated with check-valve.
\end{abstract}

Keywords: check-valve; flapping wing; high lift device

\section{Introduction}

Through the research of more than two decades, flapping wing micro air vehicles (FWMAVs) made recently great progress by the control of the tailless configuration. The "Delfly Nimble" [1] and the "KU Beetle" [2] are two successful examples that could perform hovering flight and some distinguished maneuvers. However, based on the flapping wing design improvement by the conventional wind tunnel testing, the forward flight and the level cruising of FWMAVs are still the most primary forms of flapping flight under investigation [3-5]. How to reduce the air drag and flight power during cruising, so as to achieve long-term flight endurance, are crucial to the development of FWMAVs [6,7].

Observed from the downstroke and upstroke motions of a full flapping cycle, most of the researchers performed lift enhancement during the downstroke period. There are several ways for lift improvement; for instance, by increasing the wing foil thickness and the camber [8], by adding wing corrugation [9], by enlarging the stroke angle [10], using wing rotation mechanisms [11], using morphing wings [12-14], by changing the 
wing materials [15-17], or by adjusting the wing stiffness along the chord-wise/span-wise direction [18]. Not many studies have been performed for the enhancement of lift through mimicking feathers [19-25] in the upstroke. The adaptive flight control of Caltech's Microbat by using check valves [23], the Festo's BionicSwift using of aerodynamic feathers similar to overlapping shingles on the roof [26,27], and the ventilated design [22] are the prominent research works in lift enhancement. Compared to the Caltech's Mircobat, the wingspan and body mass of Festo's Bionic Swift and the ventilated design [22,27] is much larger. Based on the more familiar understanding of the $20 \mathrm{~cm}$-span FWMAVs [28-30], herein we would like to qualitatively address the validity of the lift enhancement mechanism in Figure 1.

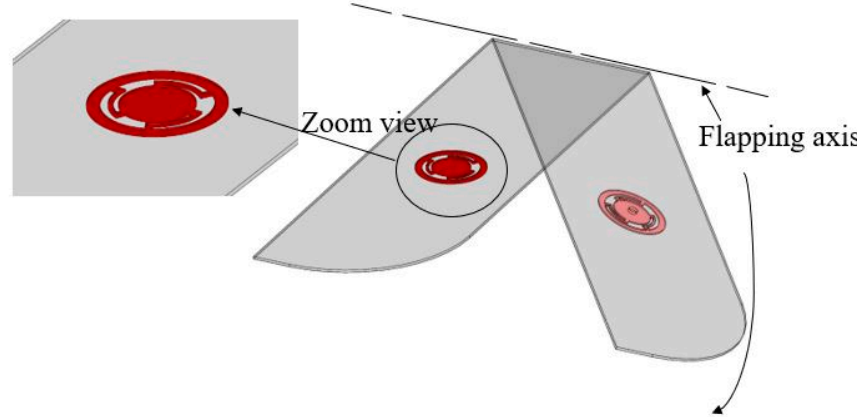

Downstroke flapping

(a)

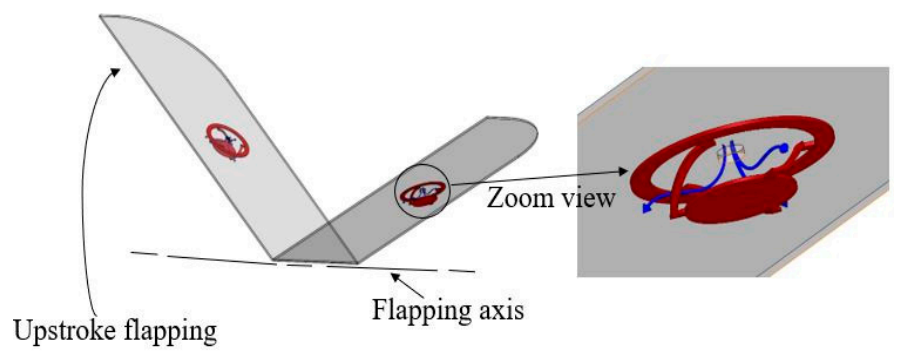

(b)

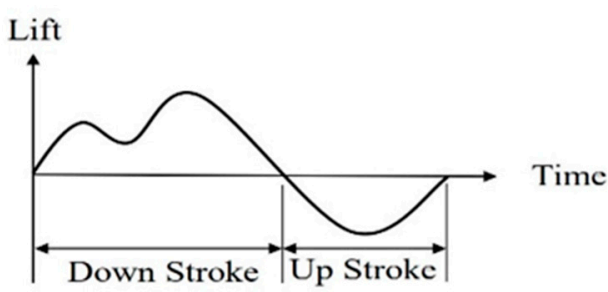

(c)

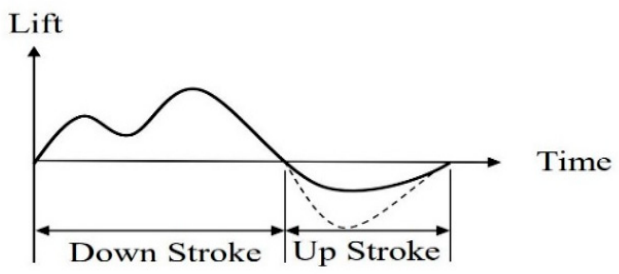

(d)

Figure 1. Illustration of check-valve closing and opening on the wing surface: (a) Check-valve closing during downstroke; (b) check-valve opening during upstroke; (c) expected lift wave form without check-valves; (d) expected lift wave form with check-valves.

Figure 1a,b illustrate the closing and opening of the check-valve during the downstroke and upstroke, respectively. The valve-opening action can effectively reduce the magnitude of the negative lift since its pin-hole opening spoils both the completeness of the wing and smoothness of the air flow. On the other hand, it also shows that the closing of check-valve during the downstroke completely restores the wing contour. It ensures that the positive lift is similar to the plain membrane wing without valves. The expected lift waveforms are shown in Figure 1c,d. In Figure 1d, dash line is the reference line shown in order to compare the region where the magnitude of the negative lift of the closed check-valve is reduced to a solid line waveform of the open check-valve case. It is evident that the proper opening and closing of the check-valves can enhance the average lift during flapping. However, there are still open issues with reference to the design of check-valves for FWMAVs. The following are limitations in comparing to the existing study [23].

Problem (i): There seems to be no baseline for the size and number of four serpentine (S) arms of the check-valves. Number 4 is not a prime number; thus, resonance may be present in this design.

Problem (ii): Other studies fail to describe the dynamic behavior of the check-valves. Therefore, it is difficult to justify the appropriateness of their design. 
Problem (iii): There are too many check-valves distributed at the leading and trailing edges of the flapping wing [31,32]. They will induce many unpredictable issues.

To eliminate these stumbling blocks, a modified design and corresponding experimental studies are conducted. In this work, the check-valve is designed by examining static and dynamic characteristics using finite element analysis (FEA). Wind tunnel experiments are conducted by incorporating the check-valves in the flapping wings and the aerodynamic performance characteristics are measured.

\section{Methodology}

\subsection{Design of Check-Valve}

The inspiration of check-valve design comes from observing the functionality of a feather in ornithology, reducing the negative lift created by ventilation $[22,23]$. The feather of the bird acts as a key factor of lift enhancement, and the structure of the feather is too complex to manufacture using traditional processing methods [33]. In this work, we adopted the disc-cap shape with three $S$ beams as the main structure of the check-valve, which is shown in Figure $2 a$ and, hence, the resonance is avoided at the central disc-cap. The annular ring, shown in Figure 2, is fixed on the lower surface of the membrane wing, which has its corresponding pin hole or orifice at the central disc-cap. The deformation of the check-valve during flapping is considered to be a dynamic problem and determining the transient solution is laborious. However, the static solutions are viable enough to perform design optimization instead of performing dynamic analysis. Hence, in this work, finite element analysis is performed for the design of the check-valve, shown in Figure 2b, which is made of PET membrane.

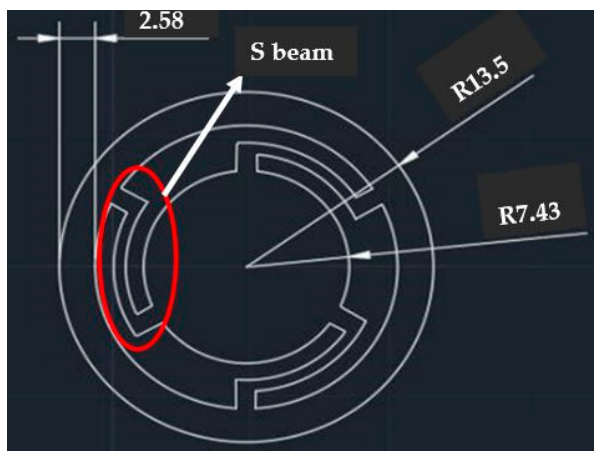

(a)

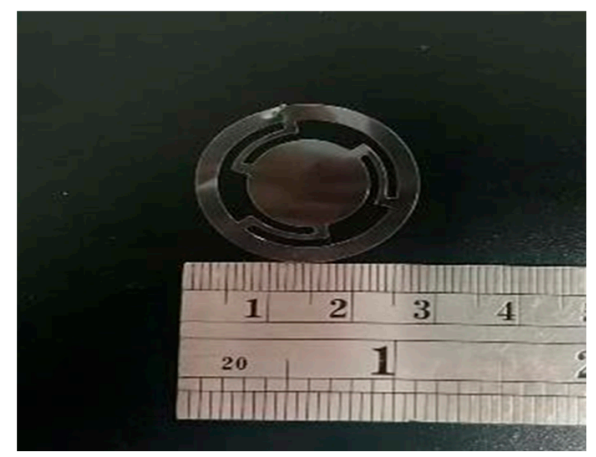

(b)

Figure 2. (a) Dimension of the check-valve (unit mm); (b) PET disc-cap made by a cutting plotter Graphtec CE5000-60.

\subsection{Frequency Response}

In general, the structural dynamics phenomenon is dealt with using the frequency response [34]. Therefore, there is no gain in $\mathrm{dB}$ according to the static solution, and the dynamic solution of the disc-cap motion can be reasonably approximated by the static solution of the check-valve disc-cap. The static and modal analyses are performed to determine the deformation and natural frequencies. The natural frequency at the first mode is experienced at $18.90 \mathrm{~Hz}$, subjected to a disc-cap radius of $7.43 \mathrm{~mm}$, which is higher than the flapping frequency $11-14 \mathrm{~Hz}$. The maximum deformation of the disc-cap is designed to be larger than the actual disc radius, ensuring that the valve is effectively opened to enhance the aerodynamic lift.

Static analysis is performed through considering the PET material for the flapping wing membrane and the corresponding mechanical properties are given in Table 1. For the ANSYS simulation, a 3-layer hexahedral mesh with 247,614 elements and 1.25 million nodes is considered to construct the finite element mesh. A simulation result, with a natural frequency of $41.78 \mathrm{~Hz}$, is shown in Figure $3 \mathrm{a}$, subject to a disc-cap radius of $4.95 \mathrm{~mm}$. Figure $3 \mathrm{~b}$ depicts the static analysis stress distribution, and the maximum stress 
experienced by the valve is $8.72 \mathrm{MPa}$ and the safety factor (=maximum stress/tensile strength) considered here is 6.3. Table 2 compares the results and significant performance measures of check-valves with different disc-cap radii. There is no natural frequency value for the plain wing as there is not a check-valve attached to it. The natural frequency of the 12 check-valves is high because the size of the radius is smaller than the 2 check-valve cases. The higher natural frequency of the 12 check-valves is reasonably calculated by considering only one check-valve out of 12 , which is $0.1 \mathrm{~g}$ for each, lighter than the 2-valve case (Table 2, second column). However, the maximum flapping frequency in the fourth column was measured from the whole behavior of wing flapping. It was smaller $(6 \mathrm{~Hz})$ in the heavier 12-valve case and larger $(14 \mathrm{~Hz})$ in the lighter 2-valve case due to the different weight loading.

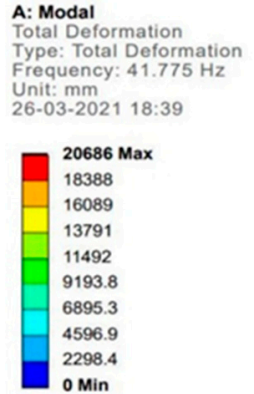

$0 \mathrm{Min}$

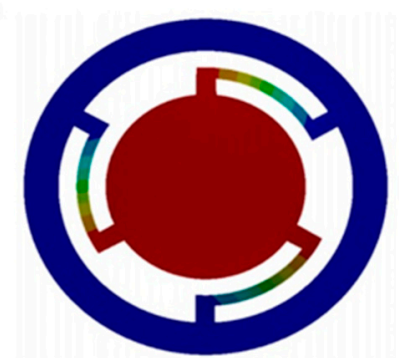

(a)

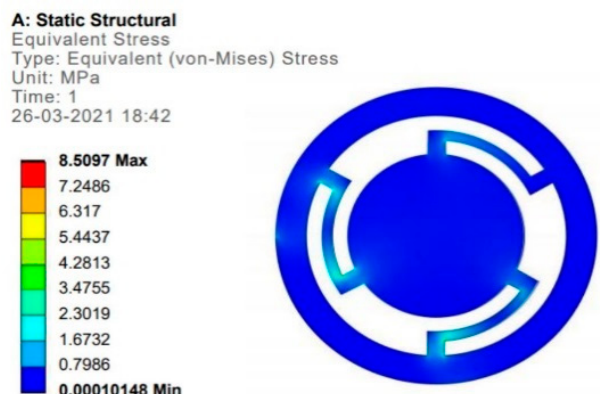

(b)

Figure 3. FEA of check-valves: (a) modal analysis; (b) static analysis.

Table 1. Material selection (PET) of check-valves (https:/ / designerdata.nl/materials/plastics/ thermo-plastics / polyethylene-terephthalate?cookie=YES (accessed on 26 March 2021)).

\begin{tabular}{ccc}
\hline Property & Value & Unit \\
\hline Density & 1250 & $\mathrm{~kg} / \mathrm{m}^{3}$ \\
Young's modulus & 2000 & $\mathrm{MPa}$ \\
Poisson's ratio & 0.37 & $\mathrm{MPa}$ \\
Tensile strength & 55 & $\mathrm{Ma}$ \\
\hline
\end{tabular}

Table 2. The performance comparison of devices with different disc-cap radii of check-valves.

\begin{tabular}{cccc}
\hline $\begin{array}{c}\text { Type of Wings with } \\
\text { Disc-Cap Radii } \\
\text { (mm) }\end{array}$ & $\begin{array}{c}\text { Total No. of } \\
\text { Check-Valves on } \\
\text { Wing (and Wing } \\
\text { Mass) }\end{array}$ & $\begin{array}{c}\text { First Natural } \\
\text { Frequency of } \\
\text { Check-Valve (Hz) }\end{array}$ & $\begin{array}{c}\text { Maximum Flapping } \\
\text { Frequency }\end{array}$ \\
\hline Plain wing & $0(0.62 \mathrm{~g})$ & - & 18 \\
4.95 & $12(1.2 \mathrm{~g})$ & 41.78 & 6 \\
7.43 & $2(0.68 \mathrm{~g})$ & 18.90 & 14 \\
\hline
\end{tabular}

\subsection{Integration of Check-Valve on the Flapping Wing}

The integration of several check-valves on the leading and trailing edges of the wing membrane induces unpredictable aerodynamic phenomena [32]. The multiple and singlepair check-valve arrangements are made of $20 \mathrm{~cm}$-span Evans mechanism-driven FWMAVs, as shown in Figure 4. The arrangement of the single pair of check-valves is modified based on the observation through high-speed photography and the instantaneous position of the central disc-cap, which is shown in Figure 5. 


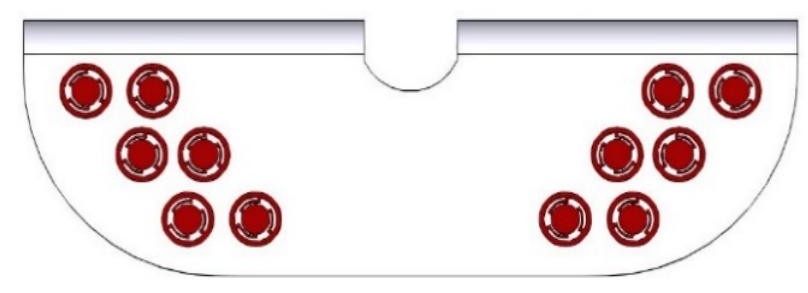

(a)

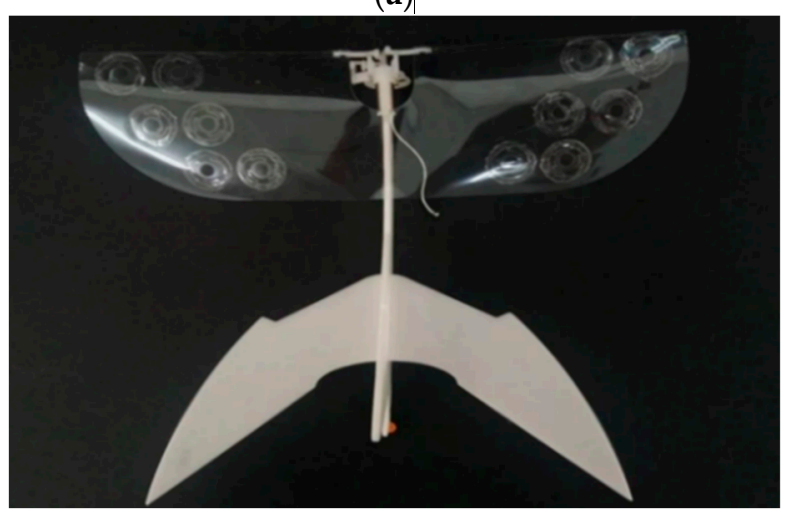

(c)

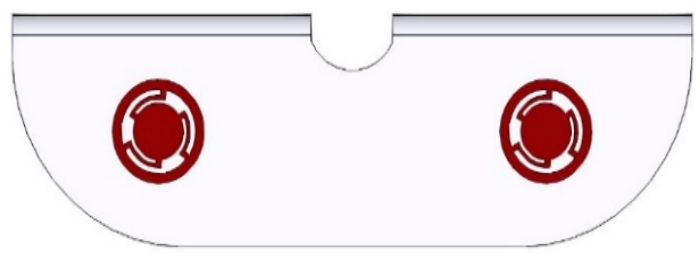

(b)

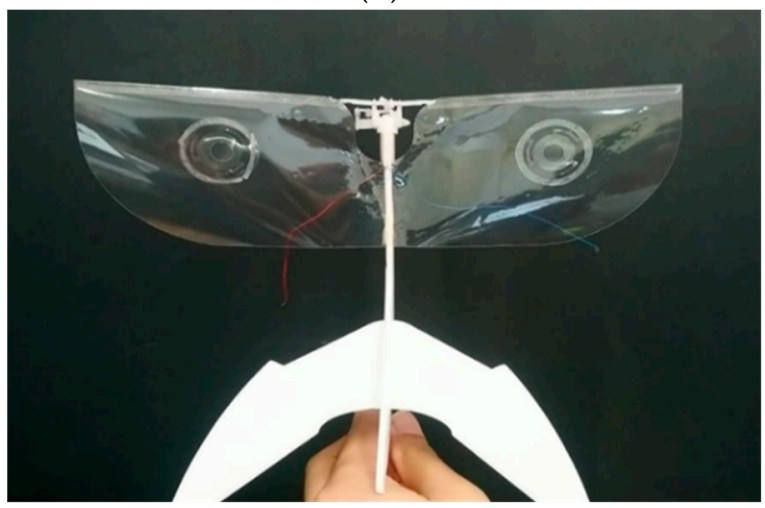

(d)

Figure 4. FWMAVs with PET wings made by a cutting plotter Graphtec CE5000-60: (a) 12 check-valve drawing; (b) 2 check-valve drawing; (c) multiple $(\times 12)$ check-valves with disc-cap radius of $4.95 \mathrm{~mm}$; (d) single-pair of check-valves with disc-cap radius of $7.43 \mathrm{~mm}$ on a wing.

\subsection{High Speed Photography}

In order to visualize the motion of the check-valves, an infallible method of identification was performed by using a high-speed camera with the capability to capture images at 1000 frames per second. The flapping wing is activated using a DC motor, which is connected to a power supply unit. Figure 5 a shows the valve opening at the beginning of the upstroke flapping motion and confirms the functional aspects of the designed check-valve. Figure $5 \mathrm{~b}$ shows that the central disc-cap deforms $(7.39 \mathrm{~mm})$ far away from the hole. Lastly, when the wing starts moving in a downstroke motion, the check-valve is closed, as shown in Figure 5c.

Though both valve designs, given in Table 2, have larger natural frequencies $(41.78 \mathrm{~Hz}$ for the $4.95 \mathrm{~mm}$ disc-cap and $18.90 \mathrm{~Hz}$ for the $7.43 \mathrm{~mm}$ disc-cap) than the flapping frequency (11-14 Hz for applying different driving voltages), the maximum deformation of the disccap has to be verified by performing the experiment. It is observed that the deformation mark in Figure 5b for the disc-cap radius of $7.43 \mathrm{~mm}$ is able to influence the surrounding air flow pattern of the check-valve; more so than in the case of the $4.95 \mathrm{~mm}$ disc-cap.

From the above results, it is found that a single-pair valve with a $7.43 \mathrm{~mm}$ disc-cap provided better performance than the multiple twelve valves with $4.95 \mathrm{~mm}$ disc-caps on the flapping wing. The drawback of a multiple $(\times 12)$ check-valve design is that it weighs more than the single-pair check-valve, as demonstrated in Table 2, and it worsens the lift enhancement, which can lower the effective lift values. To understand the applicability of flapping wings with a check-valve, the valve-switching mechanism is modified, and the corresponding flow field changes from the wing posture using high-speed photography are identified. 


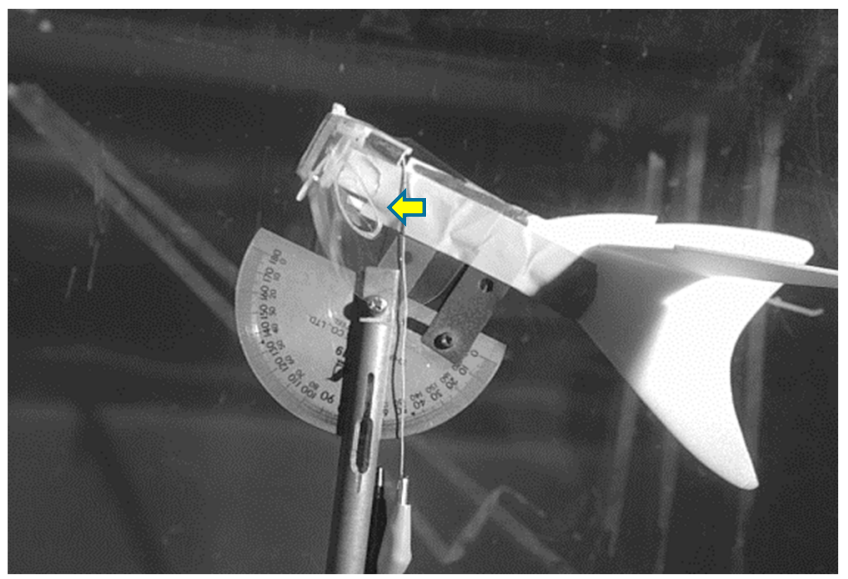

(a)

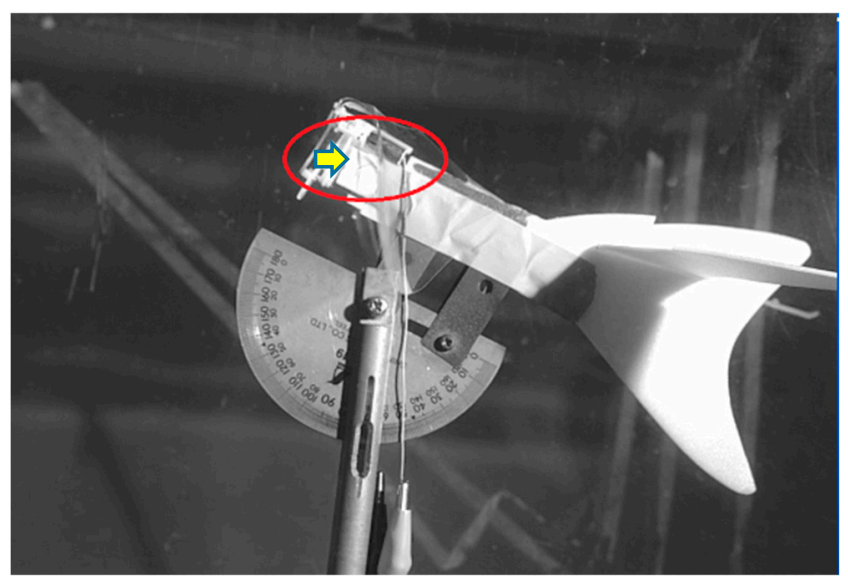

(b)

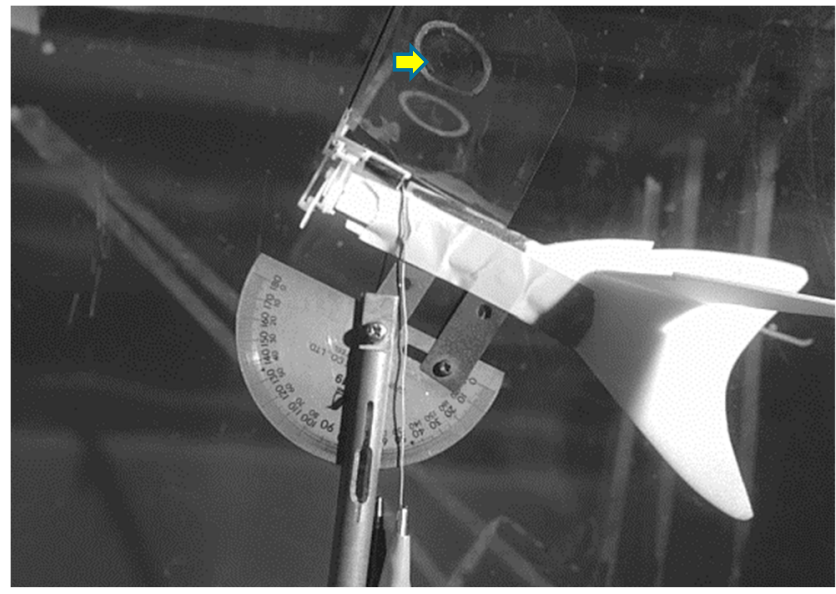

(c)

Figure 5. High speed photos of upstroke flapping: (a) Hole opening at the beginning of the upstroke; (b) central disc-cap deforms $7.39 \mathrm{~mm}$ far away from the hole during the upstroke; (c) check-valve closed at the end of the upstroke.

\subsection{Wind Tunnel Experiment}

As the result of natural frequency, wind tunnel experiments can provide tangible proof of the efficiency of valves; however, more evidence is needed to validate the hypothesis about the effectiveness of the check-valve. Though the result of frequency is satisfied, it is 
difficult to quantify the contribution in enhancing the lift by incorporating the check-valve. The wind tunnel experiment, to measure the lift and net thrust, can be a useful indicator with respect to flapping motion characteristics. The wind tunnel, shown in Figure 6, has a contraction ratio of 6.25 with a test section of $30 \mathrm{~cm} \times 30 \mathrm{~cm} \times 100 \mathrm{~cm} \mathrm{[3,9,28-30].} \mathrm{The}$ wind tunnel experiment was conducted for the two cases with and without check-valves of FWMAV. The following are the testing conditions considered for the present study:

- Wind speed: $0.5-3.0 \mathrm{~m} / \mathrm{s}$;

- $\quad$ Driving voltage: $3.0 \mathrm{~V}, 3.4 \mathrm{~V}$ and $3.7 \mathrm{~V}$;

- Inclined angle of the FWMAV: $20^{\circ}, 30^{\circ}, 50^{\circ}, 60^{\circ}$ and $70^{\circ}$.

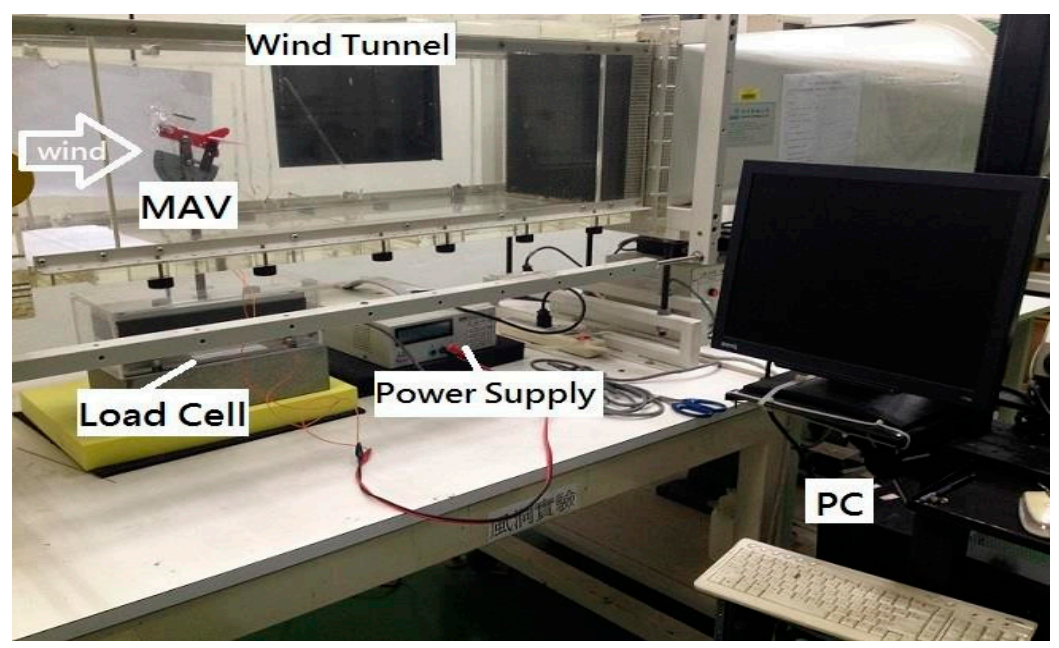

Figure 6. Wind tunnel experiment set up.

\section{Results}

\subsection{Instantaneous Lift Wave Forms and the Averaged Aerodynamic Forces}

The lift data, measured for these two cases with and without check valves, are depicted in Figure 7. The lift waveforms correspond to the flapping wing at an inclined angle of $30^{\circ}$ for a $3.7 \mathrm{~V}$ driving voltage. It is observed from these plots that the original negative lift parts, shown in Figure 7(a1,b1,c1), are shifted positively, shown in Figure 7(a2,b2,c2), using the check-valve action, which is similar to the lift enhancement principle alluded to in the expected lift waveforms shown in Figure 1. The wind tunnel data are processed in MATLAB software using an LPF (low pass filter) with a noise cut-off frequency of $30 \mathrm{~Hz}$. However, only one set of lift waveforms in Figure 7 is not sufficient to evaluate the overall lift enhancement of the check-valve action. We collected full data of lift and net thrust, according to different testing conditions, and obtained their average values. Figure 8 (without check-valve) and Figure 9 (with check-valve) are plotted by considering the time-average of more than 100 flapping cycles for each data point $[3,4]$.

The lift data are plotted in the left column of Figures 8 and 9, whereas the thrust data, shown in the right column of Figures 8 and 9, are actually termed as the net thrust, which is defined as the thrust subtracting the air drag. From the graph plotted, we can see that the lift values increase and the net thrust values decrease with the increase in wind speed. The lift and net thrust are output from the 6-axis force gauge of the wind tunnel facility, shown in Figure 6. Wind tunnel data provide a reference of predicting the aerodynamic lift of MAVs on the ground. The maximum values, shown in Figures 8 and 9, may not be used in actual steady flight or the cruising state. Whether the lift is being used or not depends on the corresponding net thrust value (restated, net thrust = thrust minus drag.) We often select the data points with zero net thrust to determine the cruising conditions of the FWMAV. Under these conditions, the thrust is equal to air drag and no more acceleration is applied to the FWMAV. The FWMAV will keep flying at a constant cruising speed. 
In addition, there is a non-linear hysteresis between the driving voltage and the flapping frequency for the FWMAV [35]. As regards acquiring flapping control, we adopted conditions of driving voltage and the flapping frequency that are accordingly expressed within a range. (The flapping frequency could be reversely obtained with the time-changing signals of lift or thrust.) Thus, the corresponding flapping frequency is not mentioned in the paper.

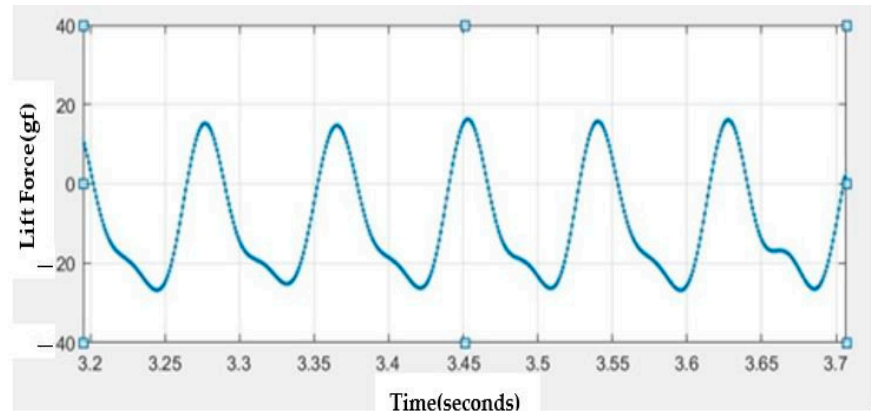

(a1)

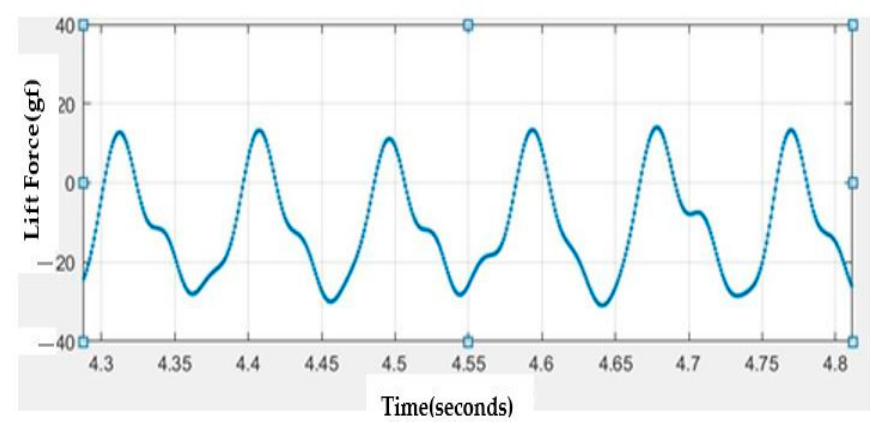

(b1)

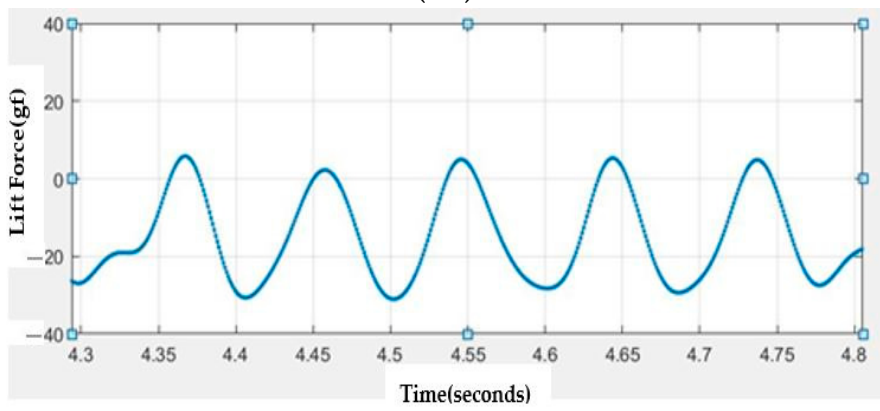

(c1)

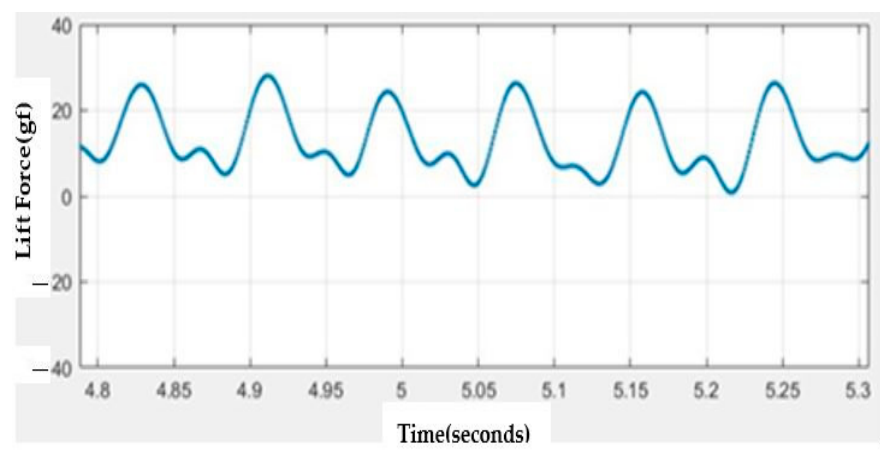

(a2)

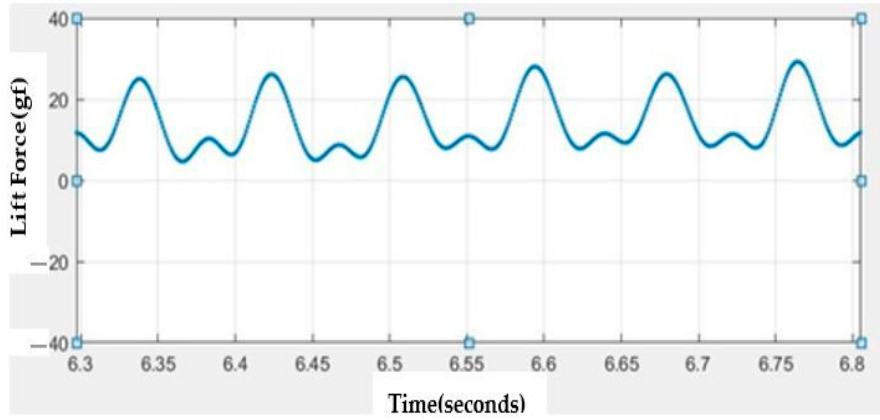

(b2)

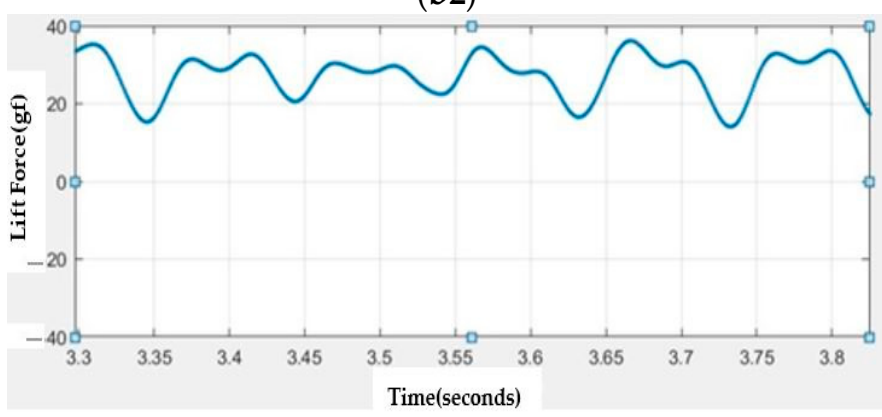

(c2)

Figure 7. (Left) Lift wave forms without check-valves subject to inclined angle of $30^{\circ}$ and driving voltage of $3.7 \mathrm{~V}$ : (a1) 1.5 $\mathrm{m} / \mathrm{s}$; (b1) $2.0 \mathrm{~m} / \mathrm{s}$; (c1) $3.0 \mathrm{~m} / \mathrm{s}$. (Right) Lift wave forms with check-valves subject to inclined angle of $30^{\circ}$ and driving voltage of $3.7 \mathrm{~V}$ : (a2) $1.5 \mathrm{~m} / \mathrm{s} ;$ (b2) $2.0 \mathrm{~m} / \mathrm{s} ;$ (c2) $3.0 \mathrm{~m} / \mathrm{s}$.

\subsection{Identification of Cruising Condition}

The following section describes the procedure used to determine the cruising condition:

- Select a curve in Figure 8 or Figure 9 with respect to the specific driving voltage and inclined angle;

- Identify the cruising speed by observing the intercepted point with zero net thrust on the net thrust diagram (marked with $\star$ or $\star$ );

- Find the corresponding cruising lift from the identified condition on the lift diagram (marked with $\star$ or $\star$ ).

Table 3 shows the cruising speed and cruising lift values with respect to different driving voltages, various inclined angles for both with and without check valve cases that 
are for all cruising conditions derived from the aerodynamic data shown in Figures 8 and 9. In the third and fourth column of Table 3, sometimes neither cruising speed nor lift corresponding to the zero net thrust are visible; or, the deduced cruising lift is too small ( $<10$ gf) to support the body weight of the FWMAV ("cannot fly".) We prepared a remark column which mentions they cannot fly, all negative net thrust, improper trend, and all positive net thrust conditions. The reasons for failure in cruising condition selection are clarified as follows:

(a)

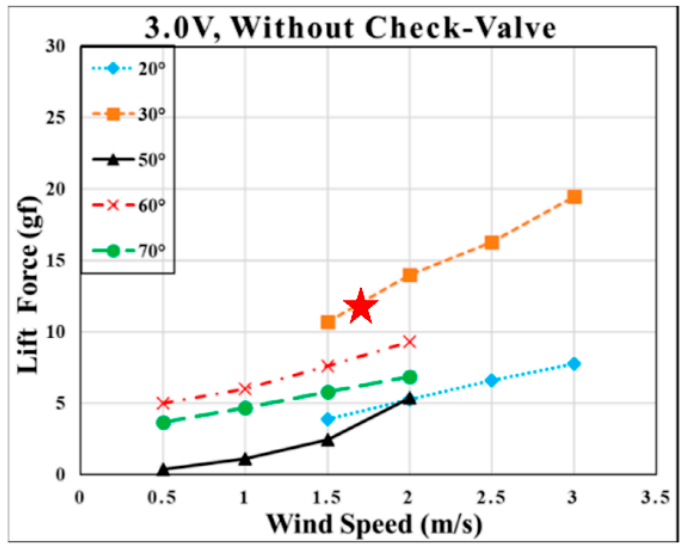

(a1)

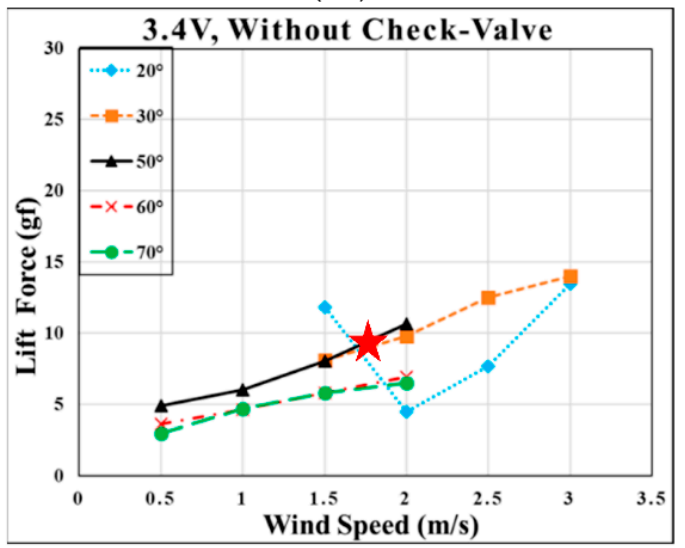

(b1)

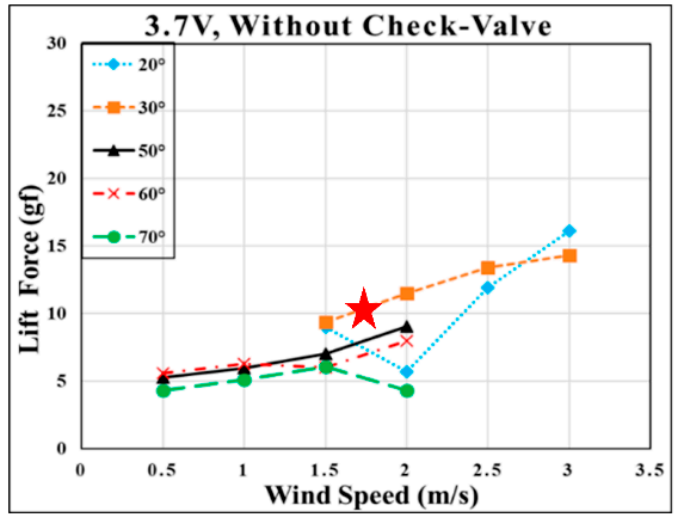

(c1)

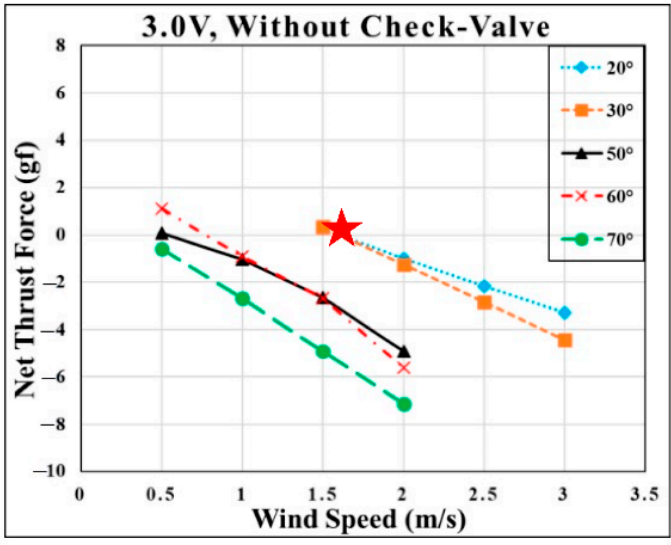

(a2)

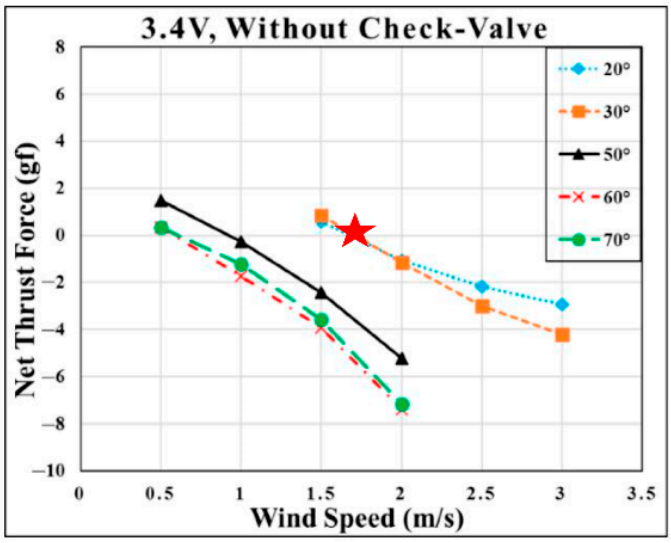

(b2)

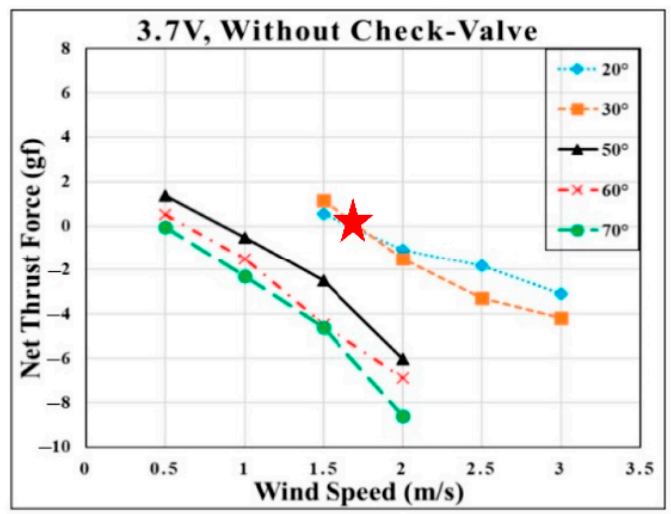

(c2)

Figure 8. The lift and net thrust, subject to the wing without check-valves, for various driving voltages: (a) $3.0 \mathrm{~V}$; (b) $3.4 \mathrm{~V}$; (c) $3.7 \mathrm{~V}$. 
- Improper trend: In the cases of $3.4 \mathrm{~V}-30^{\circ}$ and $\mathrm{V}-60^{\circ}$, and $3.7 \mathrm{~V}-50^{\circ}$ for the check-valve, the net thrust increases with the increase in wind speed. However, this trend is irrational because, in general, drag increases with wind speed. Hence, the cruising condition is not found.

- All negative (-) net thrust: In the case of $3.0 \mathrm{~V}-70^{\circ}$ without a check-valve, the net thrust data are all negative. Therefore, neither the intercept of zero net thrust nor the cruising condition can be found. A similar issue also occurs in the case of $3.4 \mathrm{~V}-20^{\circ}$ with the check-valve.

- All positive (+) net thrust: In the case of $3.4 \mathrm{~V}-70^{\circ}$ with a check-valve, the net thrust data are all positive. Therefore, neither the intercept of zero net thrust nor the cruising condition can be found.

(a)

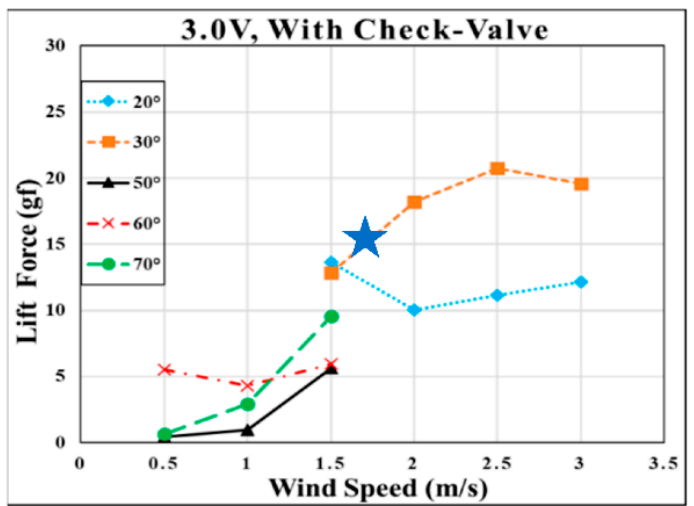

(a1)

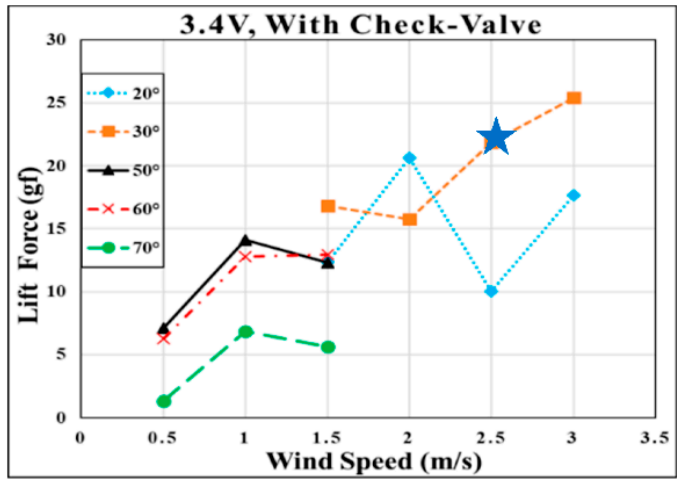

(b1)

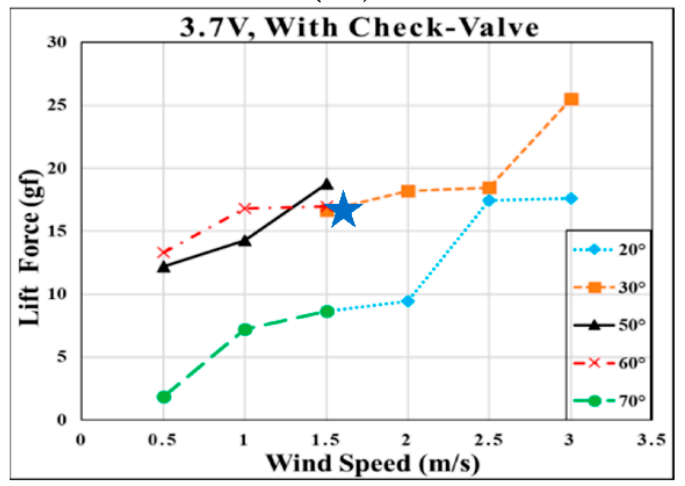

(c1)

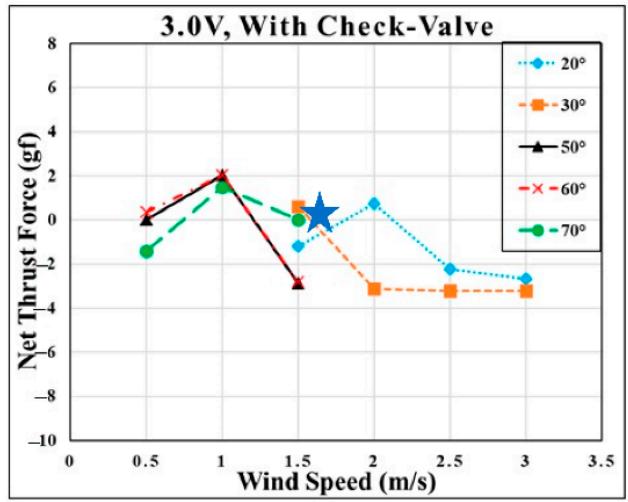

(a2)

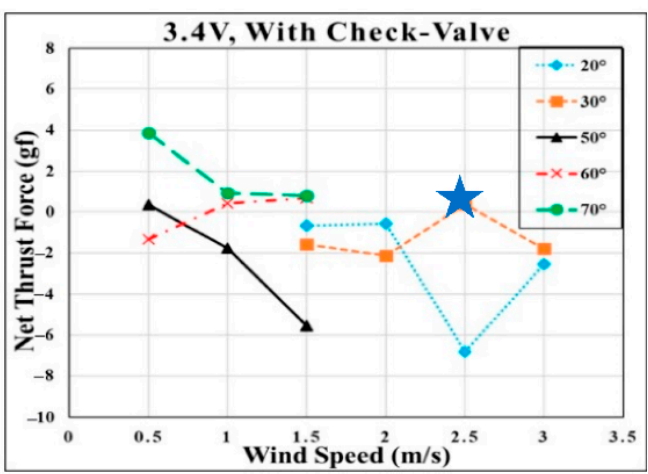

(b2)

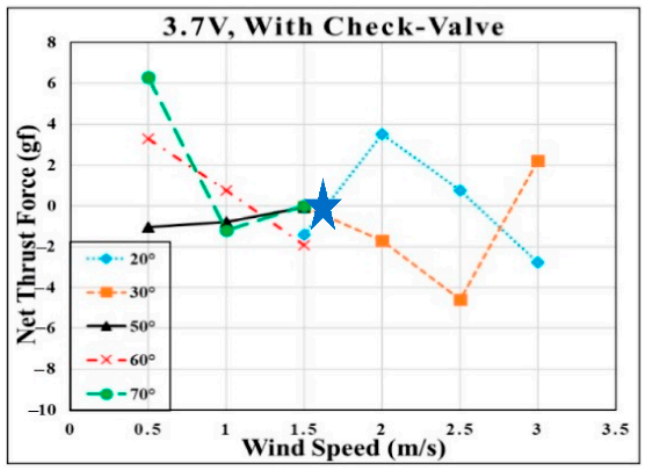

(c2)

Figure 9. The lift and net thrust subjected to the wing with check-valves for various driving voltages: (a) $3.0 \mathrm{~V}$; (b) $3.4 \mathrm{~V}$; (c) $3.7 \mathrm{~V}$. 
Finally, we identified that, for the case of $\left(3.0 \mathrm{~V}-30^{\circ}-1.6 \mathrm{~m} / \mathrm{s}\right)$, the check-valve case generates $14 \mathrm{gf}$ lift, which is $27 \%$ higher than the $11 \mathrm{gf}$ lift of the membrane wing without a check-valve. In addition, for the case of $\left(3.7 \mathrm{~V}-30^{\circ}-1.5 \sim 1.75 \mathrm{~m} / \mathrm{s}\right)$, the check-valve case generates $17 \mathrm{gf}$ lift, which is $68 \%$ higher than the $10.1 \mathrm{gf}$ lift of the membrane wing without a check-valve. The corresponding 2D quasi steady COMSOL flow simulation is shown in Figure 10 with a freestream flow speed of $1.6 \mathrm{~m} / \mathrm{s}$, a flapping frequency of $14 \mathrm{~Hz}$ and a stroke angle of $90^{\circ}$ (the total incident velocity is $4.68 \mathrm{~m} / \mathrm{s}$ ). The computational fluid dynamics (CFD) are conducted and the velocity vectors over the airfoil for the inclined angle of $30^{\circ}$ (Figure 10a,b) and inclined angle of $90^{\circ}$ during the upstroke (Figure 10c) are depicted.

Table 3. The speed and lift during different cruising conditions (red and blue highlighted words are marked for comparison of without check-valve and with check-valve cases for acceptable lift values).

\begin{tabular}{|c|c|c|c|c|c|}
\hline $\begin{array}{l}\text { Driving Voltage } \\
\text { (V) }\end{array}$ & $\begin{array}{c}\text { Inclined Angle of } \\
\text { the Fuselage }\left({ }^{\circ}\right)\end{array}$ & $\begin{array}{l}\text { Cruising Speed } \\
(\mathrm{m} / \mathrm{s})\end{array}$ & Cruising Lift (gf) & Check-Valves? & Remark \\
\hline 3 & 20 & 1.6 & 4.2 & No & Cannot fly \\
\hline 3 & 30 & 1.6 & 11 & No & \\
\hline 3 & 50 & 0.5 & 0.3 & No & Cannot fly \\
\hline 3 & 60 & 0.75 & 5.6 & No & Cannot fly \\
\hline 3 & 70 & - & - & No & All "-" net thrust \\
\hline 3.4 & 20 & 1.7 & 9.1 & No & Cannot fly \\
\hline 3.4 & 30 & 1.79 & 9 & No & Cannot fly \\
\hline 3.4 & 50 & 0.9 & 5.8 & No & Cannot fly \\
\hline 3.4 & 60 & 0.6 & 3.9 & No & Cannot fly \\
\hline 3.4 & 70 & 0.6 & 3.5 & No & Cannot fly \\
\hline 3.7 & 20 & 1.65 & 7.8 & No & Cannot fly \\
\hline 3.7 & 30 & 1.75 & 10.1 & No & \\
\hline 3.7 & 50 & 0.9 & 6 & No & Cannot fly \\
\hline 3.7 & 60 & 0.6 & 5.8 & No & Cannot fly \\
\hline 3.7 & 70 & 0.5 & 4.1 & No & Cannot fly \\
\hline 3 & 20 & 2.2 & 11 & Yes & \\
\hline 3 & 30 & 1.6 & 14 & Yes & \\
\hline 3 & 50 & 1.3 & 3 & Yes & Cannot fly \\
\hline 3 & 60 & 1.3 & 5.1 & Yes & Cannot fly \\
\hline 3 & 70 & 0.75 & 2 & Yes & Cannot fly \\
\hline 3.4 & 20 & - & - & Yes & All "-" net thrust \\
\hline 3.4 & 30 & 2.4 & 21 & Yes & Improper trend \\
\hline 3.4 & 50 & 0.6 & 7.5 & Yes & Cannot fly \\
\hline 3.4 & 60 & 0.85 & 11 & Yes & Improper trend \\
\hline 3.4 & 70 & - & - & Yes & All "+" net thrust \\
\hline 3.7 & 20 & 2.6 & 17.5 & Yes & Improper trend \\
\hline 3.7 & 30 & 1.5 & 17 & Yes & \\
\hline 3.7 & 50 & 1.5 & 19 & Yes & Improper trend \\
\hline 3.7 & 60 & 1.2 & 17 & Yes & \\
\hline 3.7 & 70 & 0.9 & 6 & Yes & Cannot fly \\
\hline
\end{tabular}




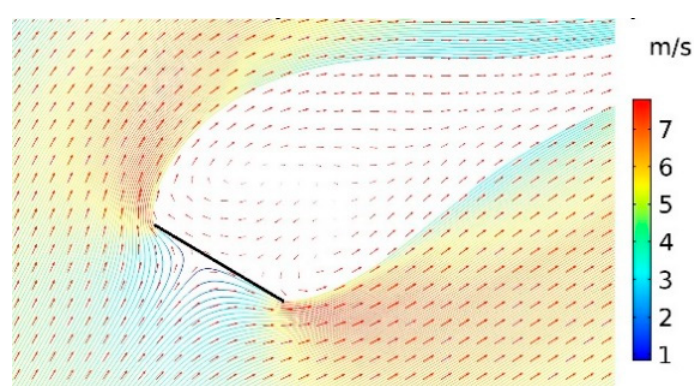

(a)

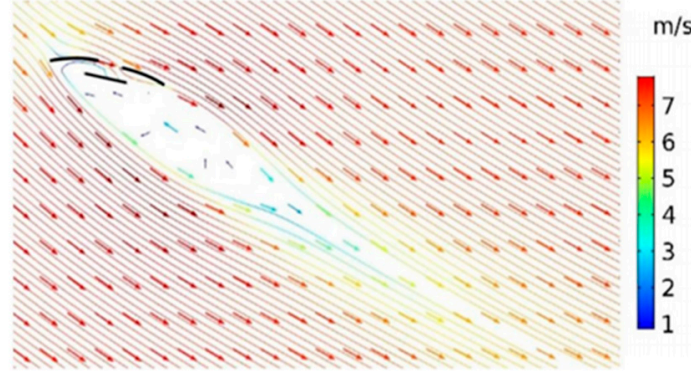

(b)

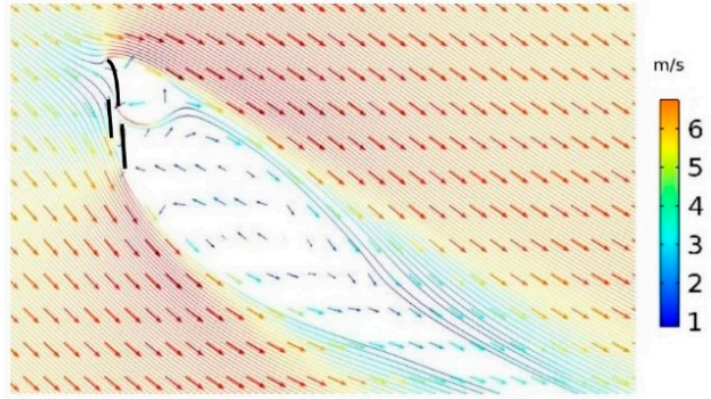

(c)

Figure 10. A 2D quasi steady COMSOL flow simulation of flapping wings according to the $30^{\circ}$ inclined fuselage, and with an upstream velocity of $1.6 \mathrm{~m} / \mathrm{s}$ and flapping frequency of $14 \mathrm{~Hz}$ (the total incident velocity is $4.68 \mathrm{~m} / \mathrm{s}$ ): (a) flow field of wing membrane with check-valve closing during downstroke, producing a lift of $9.83 \mathrm{gf}$; (b) flow field of wing membrane with check-valve opening during upstroke, producing a lift of $-4.43 \mathrm{gf}$; (c) flow field of $90^{\circ}$-inclined wing membrane with check-valve opening during upstroke, producing a lift of $3.15 \mathrm{gf}$.

\section{Discussion}

The following are the major observations and questions which arose from the experimental data:

1. It is evident from the lift waveform that the lift during upstroke presents a positive small value, rather than a negative small value, as shown in Figure $7(a 2, b 2, c 2)$.

2. At low inclined angles, the average lift and net thrust data of the wind tunnel data, observed in Figures 8 and 9, are unclear with high inclined angles.

3. The average lift and net thrust data of the wind tunnel data, shown in Figures 8 and 9, fluctuate greatly, especially under high wind speeds.

4. With massive wind tunnel data points and test conditions, only a few cruising conditions have better lift gain performance, as shown in Table 3.

5. The small size of the check-valve may not be suitable for smaller flapping wings, as shown in Figure 4a.

\subsection{The Driving Force for Opening the Check-Valve}

The check-valve is passive and it need not require external power for opening. In the conceptual design stage, shown in Figure 11a,b, it was initially considered to be the aerodynamic pressure difference that pushed the valve disc-cap open. The direction of air flowing through the valve is designed to flow from the central orifice to the outside of the valve disc-cap, and it opens in during the upstroke period. For this reason, the valve is positioned upside down on the back of the wing membrane, and the inlet air flows from top to bottom during the upstroke. Hence, the valve disc-cap is pushed (open) to adjust the lift. In addition, the valve disc-cap is attached upside down; the assistance of gravity helps with valve opening. 


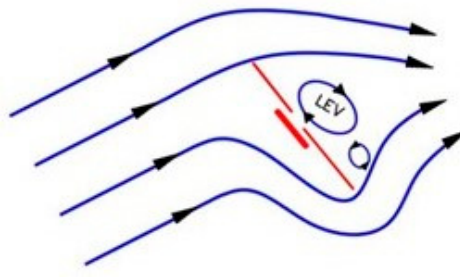

(a)

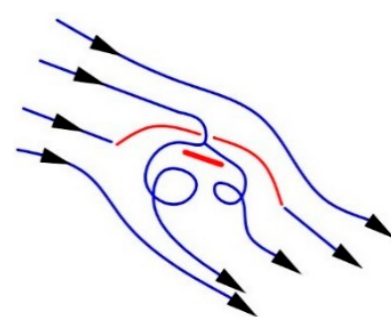

(b)

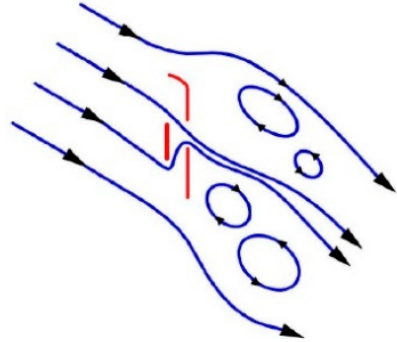

(c)

Figure 11. Concept design about the airflows on flapping wing surfaces with check valves: (a) air flow on the wing membrane with check-valve closing during downstroke, generating apparent positive lift; (b) flow separation due to checkvalve opening during upstroke of an inclined wing, producing less negative lift; (c) flow separation due to check-valve opening during upstroke of a vertical wing, producing less positive lift.

The following are the major observations during valve opening: (1) during the upstroke of the flapping wing, the horizontal free stream and the vertical downward airflow, due to flapping, are combined into a total incident velocity, which blows obliquely downward from the head top and it stops flowing in a purely vertical direction; (2) considering the inclined angle of the wing membrane during the upstroke, the inclined angle of the fuselage during the downstroke is no longer effective, but it is instead a nearly vertical pull-up movement. This can be also verified by high-speed photography. Combining the above two considerations (1) and (2), the position of the valve disc-cap is no longer facing back to the inlet airflow, but instead facing forward to the inlet airflow. The direction of the airflow through the valve in Figure 11b, on the contrary, flows from outside of the valve disc-cap into the central orifice as shown in Figure 11c. It is opened in accordance with the time of upstroke. In turn, this causes the leading-edge vortex (LEV) of the wing to be impacted and broken, reducing the lift value during the upstroke. The flow field is also changed in Figure 11c. An interesting observation is that it was originally thought that the lift of the upstroke should be negative, but the instantaneous angle of attack (AOA) of the wing, relative to the inlet airflow, was positive in Figure 11c. As the LEV intensity is reduced by the orifice jet, there is only a slight positive value. Due to this phenomenon, the lift during the upstroke shows a positive trend instead of a negative one, as shown in Figure $7(\mathrm{a} 2, \mathrm{~b} 2, \mathrm{c} 2)$, which explains the first question.

Due to this, the dominant driving force for opening the check-valve is no longer the aerodynamic pressure difference, but it is the mass inertia of the valve disc-cap itself. When the upstroke starts, the majority of the wing moves upward, but the central valve disc-cap temporarily remains in place due to its mass inertia. The valve is opened until it is largely deformed and pulled up by three S-shaped support beams, and the upstroke ends. When it returned to its reset position, the valve was closed.

\subsection{The Stability and Applicable Range of the Operation of the Check-Valve}

At high wind speed conditions, the drag increases sharply, especially when the upstream speed exceeds $2 \mathrm{~m} / \mathrm{s}$; the flapping motion is often forced to be interrupted. Regardless of whether there is a check-valve or not, when the inclined angle exceeds $50^{\circ}$, there is no average lift and net thrust data. This provides an answer to the second question. At a high inclined angle, coupled with low wind speed, the inertia of the valve disc-cap does not change much because the high inclined angle of the wing is close to the vertical pull-up posture at the time of the upstroke. Therefore, it is believed that the valve may not work smoothly under the conditions of a high inclined angle coupled with low wind speed.

During high wind speed (wind speed exceeding $2 \mathrm{~m} / \mathrm{s}$ ), with an inclined angle of less than $20^{\circ}$, the instantaneous AOA will decrease. Due to this, the valve disc-cap will be directly impacted by the inlet flow and tend to return to the original position, and also closes the valve. The change in inertia of the valve disc-cap obviously opens the valve. The valve is generally open or closed, which makes the average lift and net thrust 
data measured by the wind tunnel severely fluctuate. The reliability of the data is also questioned. This explanation illustrates the third question, which also shows that the condition of high wind speed coupled with a small inclined angle is not suitable for the operation of check-valves.

The aforementioned high inclined angle with low wind speed, and the high wind speed with small inclined angle are not applicable for check-valves. The only remaining proper application window is the medium wind speed range of $1.5-2.0 \mathrm{~m} / \mathrm{s}$ and the inclined angle is close to $30^{\circ}$. This coincides with the cruising conditions discussed in the previous section with the largest lift gain (by assigning the net thrust is zero), and it also helps to clarify the fourth question.

The argument that the check-valve is opened due to inertia means that the radius of the valve disc-cap should not be too small (considering a $20 \mathrm{~cm}$ wingspan as an example, the disc-cap radius should be around $7 \mathrm{~mm}$ ). In addition, it is known that the radius of the central orifice increases or decreases with the radius of the valve disc-cap. If the orifice is too small, it will also bring about the issue of low Reynolds number flow and high viscous fluid, so that the orifice cannot be passed through with airflow to affect the LEV and adjust the lift. The check-valve will completely malfunction. This explanation illustrates the fifth question. The inertia effect (gravitation) and the CFD are not considered in the previous modal and static analyses of FEA. If there is a more complete fluid-structure interaction (FSI) analysis tool in the future, it will fully include the effects from the valve disc-cap inertia, the aerodynamic lift/net thrust, and the supporting beam structure reaction force globally. It may be able to obtain a more satisfactory prediction of the simulation design.

Additionally, regarding the worthiness of using check-valve design in the flapping wings, evaluating the flight power may be necessary. There are several ways to measure the power consumption of the FWMAV. One is to detect the electrical power, which includes the flight power, the friction loss of the flapping mechanism and the motor loss. Figuring out how to separate flight power from the total electrical power consumption requires a lengthy description. Another means is to measure the air drag and to multiply it with flow speed to obtain flight power. However, elucidating how to separate the air drag from the "net thrust" (thrust subtracting air drag) also requires a lengthy description. Due to the limited pages of this paper, the power assumption issue can be one of the future works of our check-valve wing designs.

The real time flight testing was performed, which is shown in Figure 12. It was observed that the FWMAV with check-valves makes a sudden Immelmann turn after takeoff and generates a high lift value, which is considerably higher than the body weight of FWMAV. The experimental investigation results using this check-valve wing provides a good reference for the future design of FWMAVs maneuvering in two significant ways: (1) to allow for more payloads or batteries on the FWMAV; $(2)$ to decrease the driving voltage as well as the required power, so as to prolong flight endurance.

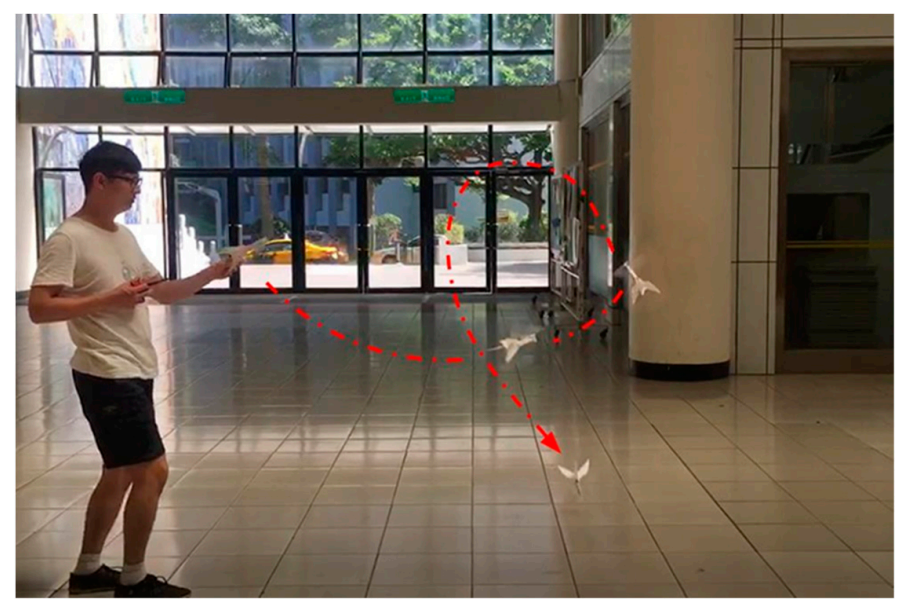

Figure 12. Flight testing of the FWMAV using check valves. 


\section{Conclusions}

The following conclusions are deduced from the experimental studies on the flapping wings with and without check-valves:

1. The check-valve design with three S-beams, and its size, play important roles in controlling lift enhancement. The single-pair design of check-valves achieved superior performance than 12-valves case.

2. Modal analysis predicted the natural frequency of the check-valve with a disc-cap radius of $7.43 \mathrm{~mm}$ as $18.90 \mathrm{~Hz}$, which is larger than the flapping frequency $11-14 \mathrm{~Hz}$. The obvious deformation of $7.39 \mathrm{~mm}$, comparable to the disc-cap radius, is verified by high-speed photography.

3. The cruising conditions of the flapping wing are identified from the generated massive wind tunnel data through observing the zero-net thrusts. During the best cruising conditions, the flapping wing with check-valves generated $27 \% \sim 68 \%$ higher lift than the membrane wing without the check-valve. A high-lift maneuver was also performed due to large lift enhancement by the check-valves.

4. In summary, the results of this study show that the lift enhancement through the incorporation of check-valve is effective for bird-like MAVs with a wingspan of about $20 \mathrm{~cm}$, rather than insect-like MAVs.

Author Contributions: Conceptualization and methodology, L.-J.Y. and B.E.; software, W.-C.W. and V.J.J.; validation, L.-J.Y. and R.W.; investigation, W.-C.W.; data curation, R.W. and N.K.U.; writingoriginal draft preparation, W.-C.W. and R.W.; writing-review and editing, L.-J.Y.; visualization, V.J.J. and N.K.U.; supervision about the power issue, C.-Y.L. and X.-H.L. All authors have read and agreed to the published version of the manuscript.

Funding: This work was supported by Taiwan's Ministry of Science and Technology by the project number MOST 107-2221-E-032-032, 109-2221-E-032-002-MY2, 109-2221-E-032-001-MY3.

Institutional Review Board Statement: Not applicable.

Informed Consent Statement: Not applicable.

Data Availability Statement: Not applicable.

Acknowledgments: The technical help from Balaji V. and Saravana K. are also acknowledged.

Conflicts of Interest: The authors declare no conflict of interest.

\section{References}

1. Narásek, M.; Muijres, F.T.; De Wagter, C.; Remes, B.D.W.; de Croon, G.C.H.E. A Tailless Aerial Robotic Flapper Reveals that Flies Use Torque Coupling in Rapid Baked Turns. Science 2018, 361, 1089-1094. [CrossRef]

2. Phan, H.V.; Park, H.C. Mechanisms of Collision Recovery in Flying Beetles and Flapping-Wing Robots. Science 2020, 370, 1214-1219. [CrossRef]

3. Yang, L.J.; Kao, A.F.; Hsu, C.K. Wing Stiffness on Light Flapping Micro Aerial Vehicles. J. Aircr. 2012, 49, 423-431. [CrossRef]

4. Yang, L.J.; Balasubramanian, E.; Waikhom, R. Inertial Effect on the Time-Averaged Lift of Flapping Wings. J. Appl. Sci. Eng. 2020, 23, 357-359.

5. He, W.; Meng, T.; He, X.; Sun, C. Iterative Learning Control for a Flapping Wing Micro Aerial Vehicle under Distributed Disturbances. IEEE Trans. Cybern. 2018, 49, 1524-1535. [CrossRef]

6. Bronz, M.; Moschetta, J.M.; Brisset, P.; Gorraz, M. Towards a Long Endurance MAV. Int. J. Micro Air Veh. 2009, 1, 241-254. [CrossRef]

7. Nguyen, Q.V.; Truong, Q.T.; Park, H.C.; Goo, N.S.; Byun, D. Measurement of Force Produced by an Insect-Mimicking FlappingWing System. J. Bionic Eng. 2010, 7, S94-S102. [CrossRef]

8. Ashraf, M.A.; Young, J.; Lai, J.C. Reynolds Number, Thickness, and Camber Effects on Flapping Airfoil Propulsion. J. Fluids Struct. 2011, 27, 145-160. [CrossRef]

9. Yang, L.J.; Kapri, N.; Waikhom, R.; Unnam, N.K. Fabrication, Aerodynamic Measurement and Performance Evaluation of Corrugated Flapping Wings. J. Aeronaut. Astronaut. Aviat. 2021, 53, 83-94.

10. Keennon, M.; Klingebiel, K.; Won, H.; Andriukov, A. Tailless Flapping Wing Propulsion and Control Development for the Nano HummingBird Micro Air Vehicle. In Proceedings of the American Helicopter Society Future Vertical Aircraft Design Conference, San Francisco, CA, USA, 18-20 January 2012. 
11. Dickinson, M.D.; Lehmann, F.O.; Sane, S.P. Wing Rotation and the Aerodynamic Basis of Insect Flight. Science 1999, $284,1954-1960$. [CrossRef]

12. Ismail, N.I.; Zulkifli, A.H.; Abdullah, M.Z.; Basri, M.H.; Abdullah, N.S. Optimization of Aerodynamic Efficiency for Twist Morphing MAV Wing. Chin. J. Aeronaut. 2014, 27, 475-487. [CrossRef]

13. Chang, E.; Matloff, L.Y.; Stowers, A.K.; Lentink, D. Soft Biohybrid Morphing Wings with Feathers Underactuated by Wrist and Finger Motion. Sci. Robot. 2020, 5, eaay1246. [CrossRef]

14. Matloff, L.Y.; Chang, E.; Feo, T.J.; Jeffries, L.; Stowers, A.K.; Thomson, C.; Lentink, D. How Flight Feathers Stick together to Form a Continuous Morphing Wing. Science 2020, 367, 293-297. [CrossRef]

15. Muhammad, A.; Nguyen, Q.V.; Park, H.C.; Hwang, D.Y.; Byun, D. Improvement of artificial foldable wing models by mimicking the unfolding/folding mechanism of a beetle hind wing. J. Bionic Eng. 2010, 7, 134-141. [CrossRef]

16. Yang, L.J.; Suseendar, M. Acoustic Comparison of PET and Latex Wings for Flapping Micro-Air-Vehicles. In Proceedings of the 10th IEEE International Conference on Nano/Micro Engineered and Molecular Systems (IEEE-NEMS), Xi'an, China, 7-11 April 2015; pp. 172-174.

17. Wei, G.; Bi, Y.; Li, X.; Xu, D.; Xu, W.; Yang, L.J.; Qin, Y.; Guo, H.; Zhao, X.; Chen, X.; et al. Self-Powered Hybrid Flexible Nanogenerator and Its Application in Bionic Micro Aerial Vehicles. Nano Energy 2018, 54, 10-16. [CrossRef]

18. Combes, S.A.; Daniel, T.L. Flexural Stiffness in Insect Wings I. Scaling and the Influence of Wing Venation. J. Exp. Biol. 2003, 206, 2979-2987. [CrossRef]

19. Yang, W.; Song, B. Experimental Investigation of Aerodynamics of Feather-Covered Flapping Wing. Appl. Bionics Biomech. 2017, 10, 3019640. [CrossRef]

20. Bachmann, T.; Emmerlich, J.; Baumgartner, W.; Schneider, J.M.; Wagner, H. Flexural Stiffness of Feather Shafts: Geometry Rules over Material Properties. J. Exp. Biol. 2012, 215, 405-415. [CrossRef]

21. Klaassen van Oorschot, B.; Choroszucha, R.; Tobalske, B. Passive Aeroelastic Deflection of Avian Primary Feathers. Bioinspir. Biomim. 2020, 15, 056008. [CrossRef]

22. Zhang, G.Q.; Yu, S.C.M. Aerodynamic Characteristics of the Ventilated Design for Flapping Wing Micro Air Vehicle. Sci. World J. 2014, 2014, 410749. [CrossRef]

23. Pornsin-Sirirak, N.; Liger, M.; Tai, Y.C.; Ho, S.; Ho, C.M. Flexible Parylene-Valved Skin for Adaptive Flow Control. In Proceedings of the Technical Digest MEMS 2002 IEEE International Conference, Fifteenth IEEE International Conference on Micro Electro Mechanical Systems, Las Vegas, NV, USA, 24 January 2002; Cat. No. 02CH37266. pp. 101-104.

24. Nickols, F.; Lin, Y.J. Feathered Tail and Pygostyle for the Flying Control of a Bio-Mimicking Eagle Bird Robot. In Proceedings of the 2017 IEEE International Conference on Cybernetics and Intelligent Systems (CIS) and IEEE Conference on Robotics, Automation and Mechatronics (RAM), Ningbo, China, 19-21 November 2017; pp. 556-561. [CrossRef]

25. Samuel, D.; Sebastien, G.; Alexandre, B.; Eric, C.; Daniel, C. Bond Graph Model of a Flapping Wing Micro Air Vehicle. In Proceedings of the 2014 IEEE/ASME 10th International Conference on Mechatronic and Embedded Systems and Applications (MESA), Senigallia, Italy, 10-12 September 2014; pp. 1-6. [CrossRef]

26. Chand, A.N.; Kawanishi, M.; Narikiyo, T. Design Analysis Modelling and Experimental Validation of a Bird-like Flapping-Wing Flying Robot. In Proceedings of the International Micro Aerial Vehicles Conference and Competition (IMAV 2014), Delf, The Netherlands, 12-15 August 2014; pp. 12-15.

27. Available online: https://www.festo.com/group/en/cms/13787.htm (accessed on 3 February 2021).

28. Yang, L.J.; Hsu, C.K.; Han, H.C.; Miao, J.M. Light Flapping Micro Aerial Vehicle Using Electrical-Discharge Wire-Cutting Technique. J. Aircr. 2009, 46, 1866-1874. [CrossRef]

29. Hsiao, F.Y.; Yang, L.J.; Lin, S.H.; Chen, C.L.; Shen, J.F. Autopilots for Ultra-Lightweight Robotic Birds-Automatic Altitude Control and System Integration of a Sub-10 g Weight Flapping-Wing Micro Air Vehicle. IEEE Control Syst. Mag. 2012, $32,35-48$.

30. Yang, L.J.; Esakki, B.; Chandrasekhar, U.; Hung, K.C.; Cheng, C.M. Practical Flapping Mechanisms for $20 \mathrm{~cm}-S p a n$ Micro Air Vehicles. Int. J. Micro Air Veh. 2015, 7, 181-202. [CrossRef]

31. Lin, J.C.-H.; Yu, F.; Tai, Y.-C. Cracking Pressure Control of Parylene Checkvalve Using Slanted Tensile Tethers. In Proceedings of the IEEE 23rd International Conference on Micro Electro Mechanical Systems (MEMS), Wanchai, Hong Kong, China, 24-28 January 2010. [CrossRef]

32. Rhie, C.M.; Chow, W.L. Numerical Study of the Turbulent Flow Past an Airfoil with Trailing Edge Separation. AIAA J. 1983, 21, 1525-1532. [CrossRef]

33. Gill, F.B. Ornithology, 3rd ed.; Macmillan, Academy of Natural Sciences: Philadelphia, PA, USA, 2007.

34. Ogata, K. Modern Control Engineering, 5th ed.; Pearson, Prentice Hall: Upper Saddle River, NJ, USA, 1997 ; p. 906.

35. Yang, L.J. The Micro-Air-Vehicle Golden Snitch and Its Figure-of-8 Flapping. J. Appl. Sci. Eng. 2012, 15, $197-212$. 